\title{
Characterization of Two Polysaccharides Having Activity on the Reticuloendothelial System from the Root of Rehmannia glutinosa
}

\author{
Masashi Tomoda, ${ }^{*}$ Hiroko Miyamoto, Noriko Shimizu, Ryōko Gonda, and Naoko Ōhara \\ Kyoritsu College of Pharmacy, Shibakōen, Minato-ku, Tokyo 105, Japan.
}

Received August 31, 1993; accepted November 4, 1993

\begin{abstract}
Two acidic polysaccharides, called rehmannan SA and rehmannan SB, were isolated from the dried root of Rehmannia glutinosa LiBoschitz. They were homogeneous on electrophoresis and gel chromatography, and their molecular masses were estimated to be $6.4 \times 10^{4}$ and $7.9 \times 10^{4}$, respectively. They were commonly composed of L-arabinose : D-galactose : L-rhamnose : D-galacturonic acid in the molar ratios of 10:10:1:1 (rehmannan SA) and 14:7:3:8 (rehmannan SB), in addition to small amounts of peptide moieties. About eighty percent (rehmannan SA) and about thirty percent (rehmannan SB) of the hexuronic acid residues exist as methyl esters. Reduction of carboxyl groups, methylation analysis, nuclear magnetic resonance and the controlled Smith degradation studies indicated the structural features of rehmannan SB, the major one in terms of the yield. It has a core structural unit of a characteristic rhamnose-rich arabino-3,6-galactan type. Both polysaccharides showed remarkable reticuloendothelial system-potentiating activity in a carbon clearance test.
\end{abstract}

Keywords polysaccharide structure; immunological activity; Rehmannia glutinosa; acidic arabinogalactan; rehmannan SB

The dried root of Rehmannia glutinosa LiBoschitz (Scrophulariaceae) is a well-known traditional crude drug used as an antasthemic, and antianemic and an antipyretic under the name of Dihuang in China (Japanese name, Kan-Jiou). Many iridoids, iridoid glucosides, ionone glucosides, a monoterpene glucoside, acteoside and a cerebroside in this crude drug have been reported. ${ }^{1-3)} \mathrm{We}$ identified and determined several monosaccharides and oligosaccharides belonging to the raffinose family in addition to many amino acids as components of the rehmannia roots. ${ }^{4,5)}$ Stachyose was found to be the main constituent of the water extract from this crude drug. However, no pure polysaccharide with biological activity has so far been obtained. The present paper describes the isolation and the activity on the reticuloendothelial system (RES) of two polysaccharides from the water extract of the dried root of Rehmannia glutinosa, and presents structural features of their major polysaccharide.

\section{Materials and Methods}

Isolation of Polysaccharides The material was imported from China. The sliced roots $(400 \mathrm{~g})$ were extracted with hot water $(4 \mathrm{l})$ with stirring for $30 \mathrm{~min}$ in a boiling water bath. After suction filtration, the residue was similarly extracted with hot water $(21)$. The filtrates were combined and the solution $(5060 \mathrm{ml})$ was added to $1 \%$ sodium sulfate $(60 \mathrm{ml}) ; 5 \%$ cetyltrimethylammonium bromide (CTAB, $860 \mathrm{ml}$ ) was then added to the solution. After centrifugation, the supernatant was poured into two volumes of ethanol. The precipitate was washed with $80 \%$ ethanol three times, centrifuged, and the final precipitate was dissolved in water and lyophilized. The yield of this fraction (CTAB-Sup) was $3.3 \mathrm{~g}$.

Fraction CTAB-Sup ( $2 \mathrm{~g}$ ) was dissolved in water and applied to a column $(5 \times 48 \mathrm{~cm})$ of diethylaminoethyl (DEAE)-Sephadex A-25 which had been pretreated as described previously. ${ }^{6)}$ After elution with water $(1.2 \mathrm{l})$, the column was eluted with $0.2 \mathrm{M}$ ammonium carbonate. Fractions of $20 \mathrm{ml}$ were collected and analyzed by the phenol-sulfuric acid method. ${ }^{7)}$ The eluates obtained from tubes 24 to 37 were combined, dialyzed, concentrated and lyophilized. Yield, $50 \mathrm{mg}$. This fraction (500 mg) was dissolved in $0.01 \mathrm{M}$ phosphate buffer ( $\mathrm{pH} \mathrm{7.2)} \mathrm{and} \mathrm{applied}$ to a column $(4 \times 30 \mathrm{~cm})$ of DEAE-Sephacel (chloride form). The column was equilibrated and eluted with the same buffer $(300 \mathrm{ml})$, then successively eluted with the phosphate buffers containing $0.1 \mathrm{M} \mathrm{NaCl}$ $(800 \mathrm{ml})$ and $0.2 \mathrm{M} \mathrm{NaCl}(800 \mathrm{ml})$. Fractions of $20 \mathrm{ml}$ were collected and analyzed by the phenol-sulfuric acid method. Eluate IIb was obtained from tubes 33 to 41 , and eluate IIc from tubes 86 to 93 . After dialysis and gel chromatography using a column $(2.6 \times 90 \mathrm{~cm})$ of Sephadex G-25 with water, fr. A was obtained from eluate IIb and fr. $B$ from eluate IIc by lyophilization of the eluates. Yields, 50 and $400 \mathrm{mg}$. Each of these fractions (100 mg each) was dissolved in $1 / 15 \mathrm{M}$ phosphate buffer ( $\mathrm{pH} 7.0$ ) containing $0.15 \mathrm{M} \mathrm{NaCl}, 1 \mathrm{mM} \mathrm{MgCl} 2$ and $1 \mathrm{mM} \mathrm{CaCl}$, and applied to a column $(1.5 \times 38 \mathrm{~cm})$ of concanavalin $\mathrm{A}$ (Con A)Sepharose (Pharmacia Co.). The column was equilibrated and eluted with the same buffer at $4{ }^{\circ} \mathrm{C}$, and fractions of $10 \mathrm{ml}$ were collected. The eluates from tubes 5 to 10 were combined, dialyzed, concentrated and applied to a column $(2.6 \times 90 \mathrm{~cm})$ of Sephadex G-25. The column was eluted with water and fractions of $20 \mathrm{ml}$ were collected. The eluates obtained from tubes 21 to 24 were combined, concentrated and lyophilized. Rehmannan SA was obtained from eluate A-I and rehmannan SB from eluate B-I (Fig. 1). Yields, $45 \mathrm{mg}$ from $50 \mathrm{mg}$ of fr. A and $312 \mathrm{mg}$ from $400 \mathrm{mg}$ of fr. B.

Polyacrylamide Gel Electrophoresis (PAGE) This was carried out in an apparatus equipped with gel tubes $(4 \times 135 \mathrm{~mm})$ and $5 \mathrm{~mm}$ Tris-glycine buffer (pH 8.3) at $5 \mathrm{~mA} /$ tube for $40 \mathrm{~min}$. Gels were stained by the periodate-Schiff (PAS) procedure and with Coomassie blue reagent. Rehmannans SA and SB gave a single clear band at distances of 48 and $55 \mathrm{~mm}$ from the origin, respectively.

Gel Chromatography The sample $(2 \mathrm{mg})$ was dissolved in a $0.1 \mathrm{M}$ Tris- $\mathrm{HCl}$ buffer $(\mathrm{pH} 7.0)$ and applied to a column $(2.6 \times 89 \mathrm{~cm})$ of Toyopearl HW-55F, pre-equilibrated and developed with the same buffer. Fractions of $5 \mathrm{ml}$ were collected and analyzed by the phenol-sulfuric acid method. Standard pullulans (Shōwa Denkō Co.) having known molecular masses were run on the column to obtain a calibration curve.

Qualitative Analysis of Component Sugars Hydrolysis and cellulose thin-layer chromatography (TLC) of component sugars were performed as described previously. ${ }^{6}$ The configurations of component neutral sugars were identified by gas chromatography (GC) of trimethylsilylated $\alpha$-methylbenzylaminoalditol derivatives. ${ }^{8)} \mathrm{GC}$ was carried out on a Shimadzu GC-14A gas chromatograph equipped with a hydrogen flame ionization detector.

Determination of Components Neutral sugars were analyzed by GC after conversion of the hydrolyzate into alditol acetates as described previously. ${ }^{9}$ Galacturonic acid was estimated by the $m$-hydroxybiphenyl method. ${ }^{10)}$ Peptide determination was performed by the method of Lowry et al. $^{1{ }^{1)}}$ using bovine serum albumin as a standard.

Determination of $\boldsymbol{O}$-Acetyl Groups The sample was hydrolyzed with $0.2 \mathrm{~N}$ hydrochloric acid in a sealed tube at $100^{\circ} \mathrm{C}$ for $2 \mathrm{~h}$. The hydrolyzate was directly applied to GC using a column $(3.2 \mathrm{~mm}$ i.d. $\times 2.1 \mathrm{~m}$ long spiral glass) packed with $5 \%$ Thermon-3000 on Shincarbon A (60 to $80 \mathrm{mesh})$ at $120^{\circ} \mathrm{C}$ with a helium flow of $30 \mathrm{ml}$ per min; $t_{\mathrm{R}}(\mathrm{min})$, acetic acid 5.2; propionic acid (internal standard) 7.9.

Determination of $\boldsymbol{O}$-Methyl Groups in Methyl Esters The sample was dissolved in $0.5 \mathrm{~N}$ sodium hydroxide containing ethanol as an internal 
standard and the solution was left at $20^{\circ} \mathrm{C}$ for $30 \mathrm{~min}$. The product was directly subjected to $\mathrm{GC}$ using a column $(3.2 \mathrm{~mm}$ i.d. $\times 2.1 \mathrm{~m}$ long spiral glass) packed with $15 \%$ polyethylene glycol (PEG) 6000 on Shimalite $F$ (40 to $80 \mathrm{mesh}$ ) at $80^{\circ} \mathrm{C}$ with a helium flow of $40 \mathrm{ml}$ per min; $t_{\mathrm{R}}(\mathrm{min})$, methanol 4.5; ethanol (internal standard) 5.7.

Nuclear Magnetic Resonance (NMR) NMR spectra were recorded on a JEOL JNM-GX270 FT NMR spectrometer in heavy water containing sodium 2,2-dimethyl-2-silapentane-5-sulfonate as an internal standard at $70^{\circ} \mathrm{C}$

Reduction of Carboxyl Groups This was carried out with 1-cyclohexyl-3-(2-morpholinoethyl)carbodiimide metho-p-toluenesulfonate and sodium borohyride as described previously. ${ }^{12)}$ The reduction was repeated three times under the same conditions. Yield was $11 \mathrm{mg}$ from $25 \mathrm{mg}$ of rehmannan SB.

Methylation This was performed with powdered sodium hydroxide and methyl iodide in dimethyl sulfoxide as described previously. ${ }^{13}$ ) The yields were $2.4 \mathrm{mg}$ from $3.0 \mathrm{mg}$ of rehmannan SB, and $4.2 \mathrm{mg}$ from $9.0 \mathrm{mg}$ of its carboxyl-reduced derivative.

Analysis of the Methylated Products The products were hydrolyzed with dilute sulfuric acid in acetic acid, then reduced and acetylated as described previously. ${ }^{14)}$ The partially methylated alditol acetates obtained were analyzed by gas chromatography-mass spectrometry (GC-MS) using a fused silica capillary column $(0.32 \mathrm{~mm}$ i.d. $\times 30 \mathrm{~m})$ of SP-2330 (Supelco Co.) with a programmed temperature increase of $4{ }^{\circ} \mathrm{C}$ per min from 160 to $220^{\circ} \mathrm{C}$ at a helium flow of $1 \mathrm{ml}$ per min. GC-MS was performed with a JEOL JMS-DX303 mass spectrometer. The relative retention times of the products with respect to 1,5-di- $O$-acetyl-2,3,4,6tetra- $O$-methyl-D-glucitol in GC are listed in Table $\mathbf{I}$.

Periodate Oxidation The polysaccharide $(180 \mathrm{mg})$ was dissolved in $0.05 \mathrm{~N}$ sodium hydroxide $(18 \mathrm{ml})$ and allowed to stand at room temperature for $30 \mathrm{~min}$, then the solution was neutralized with $5 \mathrm{M}$ acetic acid. The solution was adjusted to $45 \mathrm{ml}$ with water, then $0.1 \mathrm{M}$ sodium metaperiodate $(45 \mathrm{ml})$ was added. The reaction mixture was kept at $4^{\circ} \mathrm{C}$ in the dark, and the periodate consumption was measured by a spectrophotometric method. ${ }^{15)}$ The oxidation was completed after $4 \mathrm{~d}$. The reaction mixture was successively treated with ethylene glycol $(0.9$ $\mathrm{ml})$ at $4{ }^{\circ} \mathrm{C}$ for $1 \mathrm{~h}$ and sodium borohydride $(90 \mathrm{mg})$ at $4{ }^{\circ} \mathrm{C}$ for $16 \mathrm{~h}$, then adjustd to $\mathrm{pH} 5.0$ by addition of acetic acid. The solution was concentrated and applied to a column $(5 \times 88 \mathrm{~cm})$ of Sephadex G-25. The column was eluted with water, and fractions of $20 \mathrm{ml}$ were collected. The eluates obtained from tubes 32 to 42 were combined, concentrated and lyophilized. Yield, $150 \mathrm{mg}$.

Controlled Smith Degradation The periodate oxidation-reduction product $(75 \mathrm{mg})$ was dissolved in $0.5 \mathrm{~N}$ sulfuric acid $(7.5 \mathrm{ml})$. After standing at $22^{\circ} \mathrm{C}$ for $16 \mathrm{~h}$, the solution was neutralized with Dowex 2 $\left(\mathrm{OH}^{-}\right)$. The filtrate was concentrated and applied to a column $(5 \times 85 \mathrm{~cm})$ of Sephadex G-25. The column was eluted with water, and fractions of $20 \mathrm{ml}$ were collected. The eluates obtained from tubes 32 to 37 were combined, concentrated and lyophilized. The yield of the Smith degradation product (SDP) was $9.8 \mathrm{mg}$.

Phagocytic Activity This was measured by in vivo carbon clearance test as described previously. ${ }^{\text {) }}$ The samples and a positive control, zymosan (Tokyo Kasei Co.), were each dissolved and suspended in physiological saline and dosed i.p. ( $20 \mathrm{mg} / \mathrm{kg}$ body weight) to male mice (ICR-SPF) once a day for $5 \mathrm{~d}$.

\section{Results}

The hot water extract obtained from the dried root of Rehmannia glutinosa was treated with CTAB in the presence of small amounts of sodium sulfate. The supernatant obtained was poured into ethanol. After treatment with $80 \%$ ethanol, the precipitate obtained showed a significant RES-potentiating activity. This fraction was applied to a column chromatography of DEAE-Sephadex A-25. The stepwise elution with ammonium carbonate was carried out, and the eluate with $0.2 \mathrm{M}$ eluent was dialyzed and lyophilized. The eluate obtained contained major component polysaccharides. This fraction was applied to a column chromatography of DEAE-Sephacel, then the stepwise elution with sodium chloride in a dilute phosphate buffer was carried out. The eluates with $0.1 \mathrm{M}$ and $0.2 \mathrm{M}$ sodium chloride in a buffer were separately subjected to affinity chromatography on Con A-Sepharose for the removal of glucose-rich contaminants. A pure polysaccharide designated as rehmannan SA was obtained from the passed-through fraction of the former eluate. Another pure polysaccharide designated as rehmannan SB was obtained from the eluate with $0.2 \mathrm{M}$ sodium chloride by successive treatment with affinity and gel chromatographies similar to those of rehmannan SA. The isolation method of the two polysaccharides is summarized in Fig. 1.

Each polysaccharide gave a single band on PAGE, and a single peak on gel chromatography with Toyopearl HW-55F. Gel chromatography gave values of $6.3 \times 10^{4}$ and $7.9 \times 10^{4}$ for the molecular masses of rehmannan SA and rehmannan SB, respectively. Rehmannan SA had $[\alpha]_{\mathrm{D}}^{24}+28.6^{\circ}\left(c=0.1, \mathrm{H}_{2} \mathrm{O}\right)$ and rehmannan SB had $[\alpha]_{\mathrm{D}}^{24}$ $-37.5^{\circ}\left(c=0.1, \mathrm{H}_{2} \mathrm{O}\right)$.

Rehmannan SA and rehmannan SB are commonly composed of L-arabinose, D-galactose, L-rhamnose, D-galacturonic acid and a peptide moiety. Quantitative analyses showed that rehmannan SA contained $38.9 \%$ arabi-

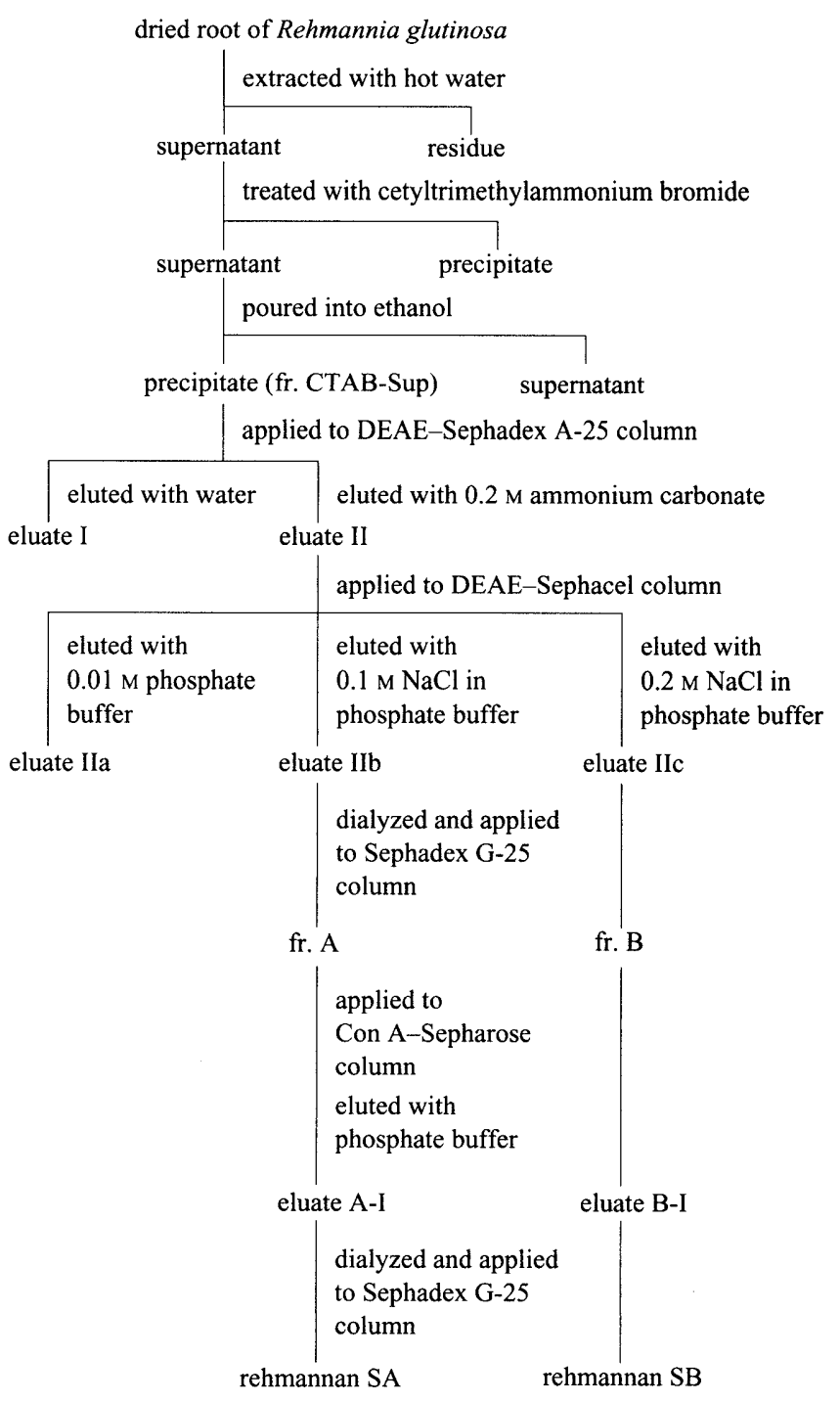

Fig. 1. Isolation of Rehmannan SA and Rehmannan SB 
nose, $46.6 \%$ galactose, $4.5 \%$ rhamnose, $5.4 \%$ galacturonic acid and $4.6 \%$ peptide moiety. The molar ratio of these component sugars was $10: 10: 1: 1$. Rehmannan SB contained $37.6 \%$ arabinose, $21.7 \%$ galactose, $9.0 \%$ rhamnose, $26.3 \%$ galacturonic acid and $5.4 \%$ peptide moiety. The molar ratio of these component sugars was $14: 7: 3: 8$.

The carbon-13 NMR $\left({ }^{13} \mathrm{C}-\mathrm{NMR}\right)$ spectra of rehmannan SA and rehmannan SB showed signals at $\delta 56.82$ and $57.05 \mathrm{ppm}$ suggesting the presence of $O$-methyl groups as carboxylic acid methyl esters. In addition, the ${ }^{13} \mathrm{C}-\mathrm{NMR}$ spectrum of rehmannan SB showed signals at $\delta 21.75$ and $177.50 \mathrm{ppm}$ suggesting the presence of $O$-acetyl groups. The presence of these groups was confirmed by GC of the hydrolyzates, and the contents of methoxyl groups were $0.7 \%$ in rehmannan SA and $1.4 \%$ in rehmannan SB. Thus existence of about $80 \%$ of the hexuronic acid residues in rehmannan SA and of about $30 \%$ of the hexuronic acid residues in rehmannan $\mathrm{SB}$ as methyl esters is evident. The content of acetyl groups was $1.0 \%$ in rehmannan SB.

Further, the ${ }^{13} \mathrm{C}-\mathrm{NMR}$ spectrum of rehmannan SA showed four anomeric signals at $\delta 100.58,101.66,106.12$ and $110.19 \mathrm{ppm}$. The first and the second were assigned to the anomeric carbons of $\alpha$-D-galactopyranosyluronic acid and $\alpha$-L-rhamnopyranose, respectively. ${ }^{16)}$ The sig-

TABLE I. Methylation Analysis of Rehmannan SB, Its Carboxylreduced Derivative and the Controlled Smith Degradation Product

\begin{tabular}{|c|c|c|c|c|}
\hline & \multirow{2}{*}{$\begin{array}{l}\text { Relative } \\
\text { retention } \\
\text { time }^{a)}\end{array}$} & \multicolumn{3}{|c|}{ Molar ratios } \\
\hline & & Original & $\begin{array}{l}\text { Carboxyl- } \\
\text { reduced }\end{array}$ & SDP \\
\hline $1,4-\mathrm{Ac}_{2}-2,3,5-\mathrm{Me}_{3}-\mathrm{L}$-arabinitol & 0.69 & 3.8 & 3.8 & 0.4 \\
\hline $1,5-\mathrm{Ac}_{2}-2,3,4-\mathrm{Me}_{3}-\mathrm{L}$-arabinitol & 0.79 & 0.2 & 0.2 & - \\
\hline $1,4,5-\mathrm{Ac}_{3}-2,3-\mathrm{Me}_{2}-\mathrm{L}$-arabinitol & 1.14 & 4.0 & 4.0 & 0.4 \\
\hline $1,2,4,5-\mathrm{Ac}_{4}-3-\mathrm{Me}-\mathrm{L}-$ arabinitol & 1.54 & 2.0 & 2.0 & - \\
\hline 1,5- $\mathrm{Ac}_{2}-2,3,4,6-\mathrm{Me}_{4}-\mathrm{D}$-galactitol & 1.10 & 0.8 & 0.8 & 1.0 \\
\hline $1,3,5-\mathrm{Ac}_{3}-2,4,6-\mathrm{Me}_{3}$-D-galactitol & 1.39 & 1.0 & 1.0 & 1.3 \\
\hline $1,4,5-\mathrm{Ac}_{3}-2,3,6-\mathrm{Me}_{3}-\mathrm{D}$-galactitol & 1.47 & 1.0 & 5.0 & - \\
\hline $1,5,6-\mathrm{Ac}_{3}-2,3,4-\mathrm{Me}_{3}-\mathrm{D}$-galactitol & 1.62 & 0.7 & 0.7 & 1.1 \\
\hline $1,2,4,5-\mathrm{Ac}_{4}-3,6-\mathrm{Me}_{2}$-D-galactitol & 1.77 & 0.3 & 0.3 & - \\
\hline $1,4,5,6-\mathrm{Ac}_{4}-2,3-\mathrm{Me}_{2}$-D-galactitol & 1.94 & 0.5 & 0.5 & - \\
\hline 1,3,5,6- $\mathrm{Ac}_{4}-2,4-\mathrm{Me}_{2}$-D-galactitol & 2.02 & 0.7 & 0.7 & 1.0 \\
\hline $1,5-\mathrm{Ac}_{2}-2,3,4-\mathrm{Me}_{3}-\mathrm{L}-\mathrm{rhamnitol}$ & 0.64 & 0.1 & 0.1 & - \\
\hline $1,2,5-\mathrm{Ac}_{3}-3,4-\mathrm{Me}_{2}-\mathrm{L}-$ rhamnitol & 0.95 & 0.6 & 0.6 & 0.8 \\
\hline 1,2,4,5-Ac 4 -3-Me-L-rhamnitol & 1.30 & 1.4 & 1.4 & 0.4 \\
\hline
\end{tabular}

a) Relative to 1,5-di- $O$-acetyl-2,3,4,6-tetra- $O$-methyl-D-glucitol. Abbreviations: $\mathrm{Ac}=$ acetyl; $\mathrm{Me}=$ methyl (e.g., 1,4-Ac $\mathrm{A}_{2}-2,3,5-\mathrm{Me}_{3^{-}}=1,4-\mathrm{di}-O$-acetyl-2,3,5-tri- $O$ methyl-).

\begin{tabular}{|c|c|c|c|}
\hline $\begin{array}{l}(\text { thirty-eight })^{a)} \\
(\text { two })^{a)}\end{array}$ & & $\begin{array}{r}\alpha \text {-L-Ara } f \\
\text { L-Ara } p\end{array}$ & $\begin{array}{l}1 \rightarrow \\
1 \rightarrow\end{array}$ \\
\hline$(\text { forty })^{a)}$ & $\rightarrow 5$ & $\alpha$-L-Ara $f$ & $1 \rightarrow$ \\
\hline$(\text { twenty })^{a)}$ & $\rightarrow 5$ & $\begin{array}{c}\alpha-\mathrm{L}-\mathrm{Ara} f \\
2 \\
\uparrow\end{array}$ & $1 \rightarrow$ \\
\hline$(\text { one })^{a)}$ & & $\alpha$-L-Rhap & $1 \rightarrow$ \\
\hline$(\operatorname{six})^{a}$ & $\rightarrow 2$ & $\alpha-\mathrm{L}-\mathrm{Rha} p$ & $1 \rightarrow$ \\
\hline & & $\begin{array}{l}\downarrow \\
4\end{array}$ & \\
\hline$(\text { fourteen })^{a)}$ & $\rightarrow 2$ & $\alpha$-L-Rhap & $1 \rightarrow$ \\
\hline$(\text { fifty-six })^{a)}$ & $\rightarrow 4$ & $\alpha-\mathrm{D}-\mathrm{Gal} p \mathrm{~A}$ & $1 \rightarrow$ \\
\hline
\end{tabular}

nals at $\delta 106.12$ and $110.19 \mathrm{ppm}$ were assigned to the anomeric carbons of $\beta$-D-galactopyranose and $\alpha-\mathrm{L}$ arabinofuranose. ${ }^{17,18)}$ In the case of the ${ }^{13} \mathrm{C}-\mathrm{NMR}$ spectrum of rehmannan SB, four anomeric signals at $\delta 100.15,101.37,106.11$ and $110.15 \mathrm{ppm}$ were shown. These were assigned to the anomeric carbons of $\alpha$-Dgalactopyranosyluronic acid, $\alpha$-L-rhamnopyranose, $\beta$ $D$-galactopyranose and $\alpha$-L-arabinofuranose, respectively. ${ }^{16-18)}$

In the present work, the authors examined the structural features of the major polysaccharide, rehmannan SB. The carboxyl groups of hexuronic acid residues in the polysaccharide were reduced to give the corresponding neutral sugar residues. ${ }^{19)}$ Both rehmannan SB and its carboxyl-reduced derivative were methylated with solid sodium hydroxide and methyl iodide in dimethyl sulfoxide. $^{20)}$ The methylated products thus obtained were hydrolyzed, then converted into partially methylated alditol acetates. Analysis by GC-MS gave the results shown in Table I.

These results indicated that the minimal unit of rehmannan SB is composed of fifteen kinds of component sugar units, as shown in Chart 1.

To elucidate the arabinogalactan core structure of rehmannan SB, the polysaccharide was subjected to periodate oxidation. The product was reduced and treated with dilute sulfuric acid under a mild condition, and the controlled Smith degradation product (SDP) was obtained.

SDP gave a single peak on gel chromatography, and it showed a value of $3.8 \times 10^{4}$ for the molecular mass. The result of analysis showed that SDP was composed of $\mathrm{L}$-arabinose, $\mathrm{D}$-galactose and L-rhamnose in the molar ratio of $2: 11: 3$.

SDP was methylated under conditions similar to those of the original polysaccharide. The product obtained was hydrolyzed and converted into partially methylated alditol acetates. The result of analysis by GC-MS is also shown in Table I. This result indicated that the minimal unit of SDP is composed of eight kinds of component sugar units, as shown in Chart 2.

The effects of rehmannan SA and rehmannan SB on the RES were demonstrated by a modification ${ }^{9)}$ of the in vivo carbon clearance test ${ }^{21)}$ using zymosan as a positive control. As shown in Fig. 2, the phagocytic indices were markedly increased, suggesting activation of the RES by i.p. administration of these polysaccharides.

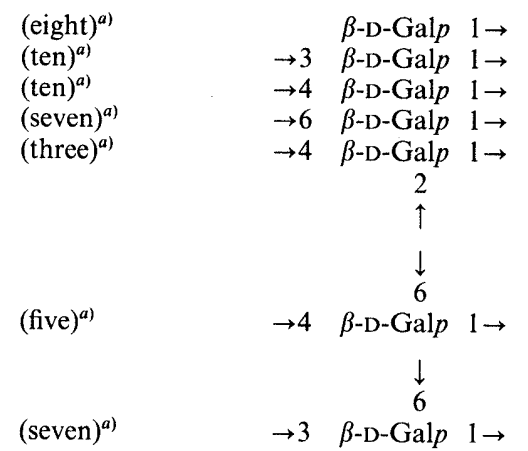

Chart 1. Component Sugar Residues in the Minimal Unit in the Structure of Rehmannan SB

a) Number of residues. Araf, arabinofuranose; Arap, arabinopyranose; Gal $p$, galactopyranose; Rhap, rhamnopyranose; Gal $p$ A, galactopyranosyluronic acid. 


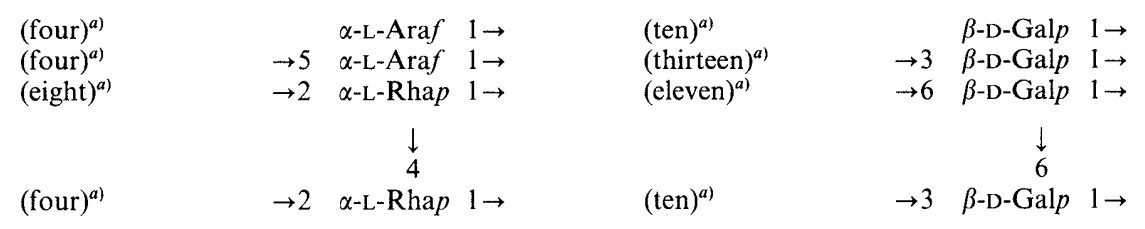

Chart 2. Component Sugar Residues in the Minimal Unit in the Structure of the Controlled Smith Degradation Product a) Number of residues.

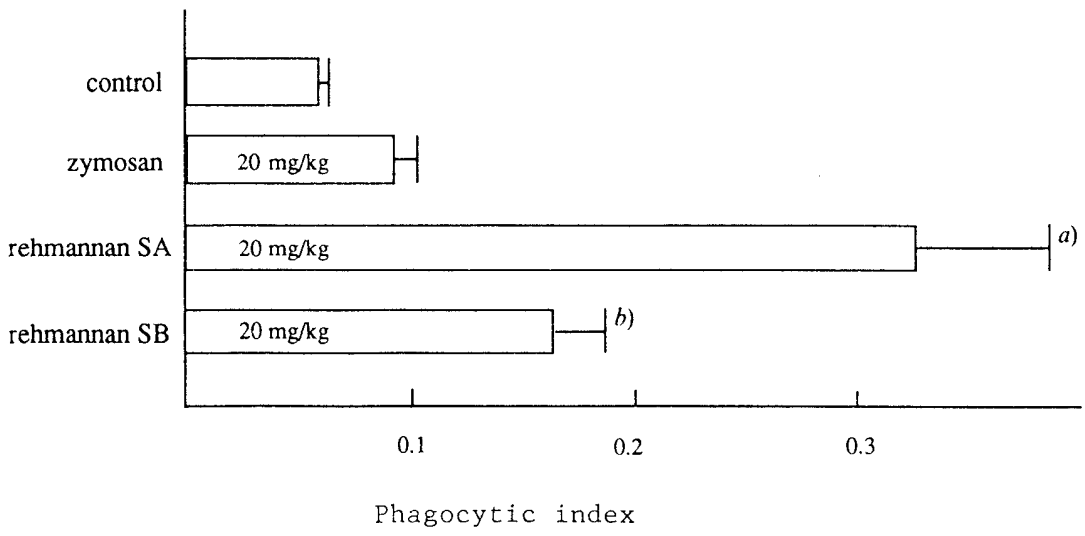

Fig. 2. Effects of Rehmannan SA and Rehmannan SB on Phagocytosis

Significantly different from the control, a) $p<0.01 ; b) p<0.001$.

\section{Discussion}

During our studies on the immunologically active polysaccharides in crude drugs obtained from various plant sources, twenty-seven substances have been isolated as RES-activating polysaccharides, and their structural features elucidated. The majority of them belong to acidic arabino-3,6-galactan type polysaccharides. Those are saposhnikovan A from the root and rhizome of Saposhnikovia divaricata, ${ }^{\text {) }}$ MVS-IIIA, -IVA and -VI from the seed of Malva verticillata, ${ }^{22-24)}$ ukonans A, B and $\mathrm{C}$ from the rhizome of Curcuma longa ${ }^{25-27)}$ glycyrrhizans UA, UB and GA from the root of Glycyrrhiza uralensis and the stolon of G. glabra var. glandulifera ${ }^{18,28)}$ eucomman A from the bark of Eucommia ulmoides, ${ }^{29)}$ AMon-S from the root of Astragalus mongholicus, ${ }^{30}$ ) cnidirhan AG from the rhizome of Cnidium officinale, ${ }^{31)}$ ginsenans PA, PB, S-IA and S-IIA from the root of Panax ginseng, ${ }^{32,33)}$ and peonan SB from the root of Paeonia lactiflora. ${ }^{34)}$

Among these RES-activating polysaccharides, saposhnikovan A, MVS-IIIA and -IVA, ukonans A and B, AMon-S, cnidirhan AG, and ginsenans PA and PB have typical arabino-3,6-galactan moieties as their main constituents. As the other characteristic component arabinose units, terminal L-arabinopyranose is found in glycyrrhizans UA and UB, and $\alpha-2,5-$ or 3,5-branched L-arabinofuranosyl residues are present in MVS-VI, ukonan C, glycyrrhizan GA, ginsenans S-IA and S-IIA, and peonan SB. In addition to the usual galactosyl units in a typical arabino-3,6-galactan, both $\beta$-1,4-linked and 2,4- or 3,4branched D-galactopyranosyl residues occur in ukonan $C$, glycyrrhizan UB, eucomman A, ginsenans S-IA and S-IIA, and peonan SB.

Rehmannan SB also possesses a few terminal L-arabinopyranosyl and considerable $\alpha-2,5$-branched L-ara- binofuranosyl residues in addition to the usual terminal and $\alpha-1,5$-linked L-arabinofuranosyl units. The occurrence of three kinds of branching $\mathrm{D}$-galactosyl residues, i.e., $\beta-2,4-, 3,6$ - and 4,6-branches, in this substance is the first example among the known RES-activating polysaccharides.

The controlled Smith degradation of rehmannan SB gave a product having a typical $\alpha-1,5$-linked L-arabino$\beta-3,6$-branched D-galactan structure. This product can also be classified under a novel type of arabino-3,6galactan having relatively high content of $\alpha-1,2$-linked and 2,4-branched L-rhamnosyl residues. Thus the core galactan-type structure of rehmannan SB is characteristic, because no rhamnose was found in the core galactan structures of ukonans $\mathrm{B}$ and $\mathrm{C},{ }^{35,36)}$ glycyrrhizans UA and GA, ${ }^{37,38)}$ MVS-VI, ${ }^{39)}$ or cnidirhan AG. ${ }^{31)}$

Further studies of the relationship between the structure of rehmannan SB and its activity are in progress.

References

1) I. Kitagawa, Y. Fukuda, T. Taniyama, M. Yoshikawa, Chem. Pharm. Bull., 34, 1399 (1986).

2) M. Yoshikawa, Y. Fukuda, T. Taniyama, I. Kitagawa, Chem. Pharm. Bull., 34, 1403 (1986).

3) M. Yoshikawa, Y. Fukuda, T. Taniyama, B. C. Cha, I. Kitagawa, Chem. Pharm. Bull., 34, 2294 (1986).

4) M. Tomoda, S. Katō, M. Ōnuma, Chem. Pharm. Bull., 19, 1455 (1971).

5) M. Tomoda, M. Tanaka, N. Kondō, Chem. Pharm. Bull., 19, 2411 (1971).

6) M. Tomoda, S. Kaneko, M. Ebashi, T. Nagakura, Chem. Pharm. Bull., 25, 1357 (1977).

7) M. Dubois, K. A. Gilles, J. K. Hamilton, P. A. Rebers, F. Smith, Anal. Chem., 28, 350 (1956)

8) R. Oshima, J. Kumanotani, C. Watanabe, J. Chromatogr., 259, 159 (1983)

9) N. Shimizu, M. Tomoda, R. Gonda, M. Kanari, N. Takanashi, N. Takahashi, Chem. Pharm. Bull., 37, 1329 (1989). 
10) N. Blumenkrantz, G. Asboe-Hansen, Anal. Biochem., 54, 484 (1973).

11) O. H. Lowry, N. J. Rosebrough, A. L. Farr, R. J. Randall, J. Biol. Chem., 193, 265 (1951).

12) M. Tomoda, M. Ichikawa, Chem. Pharm. Bull., 35, 2360 (1987).

13) N. Shimizu, H. Asahara, M. Tomoda, R. Gonda, N. Ohara, Chem. Pharm. Bull., 39, 2630 (1991).

14) M. Tomoda, K. Shimada, Y. Saito, M. Sugi, Chem. Pharm. Bull., 28, 2933 (1980).

15) G. O. Aspinall, R. J. Ferrier, Chem. Ind. (London), 1957, 1216.

16) N. Shimizu, M. Tomoda, Chem. Pharm. Bull., 33, 5539 (1985).

17) K. Bock, C. Pedersen, H. Pedersen, "Advances in Carbohydrate Chemistry and Biochemistry," Vol. 42, ed. by R. S. Tipson, D. Horton, Academic Press Inc., London, 1984, pp. 193-214.

18) N. Shimizu, M. Tomoda, M. Satoh, R. Gonda, N. Ohara, Chem. Pharm. Bull., 39, 2082 (1991).

19) R. L. Taylor, H. E. Conrad, Biochemistry, 11, 1383 (1972).

20) I. Ciucanu, F. Kerek, Carbohydr. Res., 131, 209 (1984).

21) G. Biozzi, B. Benacerraf, B. N. Halpern, Br. J. Exp. Pathol., 34, 441 (1953).

22) M. Tomoda, M. Kanari, R. Gonda, N. Shimizu, Phytochemistry, 28, 2609 (1989).

23) R. Gonda, M. Tomoda, N. Shimizu, M. Kanari, Planta Medica, 56, 73 (1990).

24) R. Gonda, M. Tomoda, M. Kanari, N. Shimizu, H. Yamada, Chem. Pharm. Bull., 38, 2771 (1990).

25) M. Tomoda, R. Gonda, N. Shimizu, M. Kanari, M. Kimura,
Phytochemistry, 29, 1083 (1990).

26) R. Gonda, M. Tomoda, N. Shimizu, M. Kanari, Chem. Pharm. Bull., 38, 482 (1990).

27) R. Gonda, M. Tomoda, Chem. Pharm. Bull., 39, 441 (1991).

28) M. Tomoda, N. Shimizu, M. Kanari, R. Gonda, S. Arai, Y. Okuda, Chem. Pharm. Bull., 38, 1667 (1990).

29) R. Gonda, M. Tomoda, N. Shimizu, M. Kanari, Chem. Pharm. Bull., 38, 1966 (1990).

30) N. Shimizu, M. Tomoda, M. Kanari, R. Gonda, Chem. Pharm. Bull., 39, 2969 (1991).

31) M. Tomoda, N. Ōhara, R. Gonda, N. Shimizu, K. Takada, Y. Satoh, S. Shirai, Chem. Pharm. Bull., 40, 3025 (1992).

32) M. Tomoda, K. Takeda, N. Shimizu, R. Gonda, N. Ōhara, K. Takada, K. Hirabayashi, Biol. Pharm. Bull., 16, 22 (1993).

33) M. Tomoda, K. Hirabayashi, N. Shimizu, R. Gonda, N. Ōhara, K. Takada, Biol. Pharm. Bull., 16, 1087 (1993).

34) M. Tomoda, K. Matsumoto, N. Shimizu, R. Gonda, N. Ohara, Biol. Pharm. Bull., 16, 1207 (1993).

35) R. Gonda, M. Tomoda, K. Takada, Pharm. Pharmacol. Lett., 2, 20 (1992).

36) R. Gonda, M. Tomoda, N. Ohara, K. Takada, Biol. Pharm. Bull., 16, 235 (1993).

37) N. Shimizu, M. Tomoda, K. Takada, R. Gonda, Chem. Pharm. Bull., 40, 2125 (1992).

38) K. Takada, M. Tomoda, N. Shimizu, Chem. Pharm. Bull., 40, 2487 (1992).

39) M. Tomoda, H. Asahara, R. Gonda, K. Takada, Chem. Pharm. Bull., 40, 2219 (1992). 